Radiocarbon: Calibration and Prehistory. Edited by Trevor Watkins. Pp. vi +147 . (Edinburgh University : Edinburgh, January 1976.) £3.50.

THE tree-ring calibration of radiocarbon dating has had a number of striking archaeological consequences, bringing the historical and radiocarbon calendars for the ancient civilisations of the Old World into closer agreement and pushing the date of some cultures and monuments back much earlier than had been realised.

The intention of the symposium from which this volume springs was to "allow discussion of the subject of correction before a lay audience in terms which they could understand". Most of the contributions succeed well in this modest task. Richard Burleigh, for instance, advocates preliminary calibration for many purposes, while pointing out that for other purposes uncalibrated dates can often legitimately be compared. This view, however, is somewhat over-simplified by the editor: "it is too early to use the curves at present being bandied around as calibration curves for radiocarbon dates". Unfortunately the volume went to press before the publication by R. M. Clark of the most statistically sound and reliable of these (Antiquity, 49, 252-272, 1975).

The volume as a whole betrays a similar lack of balance. Alongside useful reviews of European dendrochronology by Fletcher and of the problem of irregularities ('kinks') by Ottaway and Ottaway, is a substantial disquisition by McKerrell (53 pages long, more than a third of the total) arguing the very special case that the existing calibration curves are reasonably sound except for the period between 2,500 BC and 1,500 $\mathrm{BC}$ (in calendar years).

This view is based on the assessment of radiocarbon and historical dates (the later derived from the Egyptian calendar) for Egypt, the Near East and the Aegean. Unfortunately the archaeology for the Agean is distinctly shaky (p61) and the treatment of the central European material (Veterov, Madarovce, and so on; p68) might have been more convincing at the hand of a professional archaeologist.
It is surprising that a scientific worker should propose, in the proceedings of a conference designed for laymen, a theory with major geophysical implications which might better first be offered to the critical scrutiny of his physicist colleagues. Moreover, when the theory that calibrated dates in general are sound (with the specific exception of a single millennium), has global implications, would it not be wise to consider the broader consequences outside of Europe?

What begins as a useful introductory handbook rapidly becomes a specialised and highly controversial critique of calibration, an argument à thèse rather than a clarification, on which the comments of competent radiocarbon specialists might have been invited. The editor could usefully have asked himself whether he wanted his book to be a searching professional critique of calibration, or a lucid, non-technical exposition. There is still a need for both.

Colin Renfrew is Professor of Archaeology at the University of Southampton, UK.

\title{
Textbook of ichnology
}

The Study of Trace Fossils: A Synthesis of Principles, Problems and Procedures in Ichnology. Edited by Robert W. Frey. Pp. xiv +562 . (Springer: Berlin and New York, 1975.) DM 141.70; $\$ 58.10$.

MANY sedimentary rocks contain fossilised branching structures that a hundred years ago were mistakenly identified as seaweeds and called 'fucoids'. In the 1880's these were shown to be the tracks of animals, and in most parts of the world their study lapsed. But in Geimany this was not at all the case. In 1925 Rudolf Richter founded a new school of Akutuopaläontologie in which the traces of animals played a vital part in the determination of environment. These early studies led to the establishment of a new and exciting discipline in which palaeontologists were able to postulate behavioural parameters. In this way 'palaeoethology' came to join 'palaeoecology' as a branch of 'geobiology'. In these studies the Germans remained far in advance of the rest of the world for over thirty years; and, indeed, it can still be said that they lead the field, with Professor Adolf Seilacher of Tübingen (who contributes a foreword to this book) as the acknowledged dean.

But at least nowadays the supremacy of our German colleagues in this field has been challenged. The discipline of palaeontology bas much changed from the time when it was dominated by morphology and taxonomy. Its boun- daries have extended, and in 1970 Crimes and Harper edited a remarkably successful symposium on trace fossils which reported the proceedings of an international symposium held in Liverpool. This was followed in 1971 by a field-guide to trace fossils produced by Louisiana State University. It has now been realised all over the world that ichnology plays a quite indispensable role in field studies aimed at interpreting past environments.

The present volume is the only textbook on the subject available in English. It captures well the excitement of a subject which to most of the world is still seen as new. The editor has kept his contributors well disciplined, so that in spite of the fact that it combines the work of no fewer than 28 authors, it retains an admirable cohesiveness as well as being comprehensive. For example, it includes chapters on both plant traces and vertebrate trails (both by William Sarieant), and concludes with a fascinating section describing two new developments in ichnologyone on experimental methods (By Christopher Elders) and the other describing George Farrow's brilliant techniques for the study of the traces of living animals in present day sediments.

This book will certainly be regarded as an indispensable teaching aid in all future courses dealing with ichnologv or palaeoethology, and the editor. Robert Frey, is to be congratulated on the clarity of exposition he has been able to command as well as the logic he 